\title{
CPW-Fed Antenna Design with Increased Bandwidth and WLAN Band-Filtering for UWB Systems
}

\author{
Naser Ojaroudi Parchin ${ }^{* 1}$, Yasir I. A. Al-Yasir' ${ }^{1}$, Haleh Jahanbakhsh Basherlou², Ahmed M. \\ Abdulkhaleq ${ }^{1}$, Fauzi Elmegri ${ }^{1}$, and Raed A. Abd-Alhameed ${ }^{1}$ \\ $\left\{\right.$ N.OjaroudiParchin@Bradford.ac.uk $\left.{ }^{1^{*}}\right\}$ \\ ${ }^{1}$ Faculty of Engineering and Informatics, University of Bradford, Bradford BD7 1DP, UK \\ ${ }^{2}$ Bradford College, Bradford, West Yorkshire, BD7 1AY, UK
}

\begin{abstract}
A compact coplanar waveguide (CPW)-fed antenna with improved bandwidth and a band-stop property is represented for ultra-wideband (UWB) communications. Its configuration is composed of a modified circular-ring radiation patch with a cross-strip and a pair of protruded arms and a semi-circular ground plane. It is designed on a lowprofile FR-4 substrate with $\delta=0.02, \varepsilon=4.4$, and $\mathrm{h}=1.6 \mathrm{~mm}$. By modifying the ground plane and also adding a cross-strip into the circular-ring radiation patch, the impedance bandwidth of the antenna for $S_{11} \leq-10$ can be improved significantly. The band-notched characteristic of the design is achieved by using the pair of protruded arms. The proposed antenna exhibits a wide usable fractional bandwidth from 3.1 to $24 \mathrm{GHz}$ and a frequency notch-band in $5.5 \mathrm{GHz}$ of WLAN systems. The performance of a $4 \times 4$ MIMO configuration for the UWB antenna is also studied and good results are achieved.
\end{abstract}

Keywords: Band-notch antenna, MIMO system, monopole antenna, WLAN, UWB communications.

\section{Introduction}

The wireless communication systems are highly developed in recent years, and the spectrum congestion has been highly increased. Ultra wide band (UWB) wireless communication has gained more attentions recently and became one of the most rapidly developing technologies in wireless applications due to several attractive advantages such as low-power, high-transmission rate, etc [1-2]. The congestion of the frequency spectrum and the interference of various communication systems are considered the most important problems due to the advancement of wireless systems and the sustainable demand for improving the operation bandwidth [3-4]. Commercially, the development of ultra-wideband systems is evident after the allocation of 3.1$10.6 \mathrm{GHz}$ by FCC for this purpose [5]. Low-profile antennas with the low-cost fabrication process and also Omni-directional radiation patterns as well as a large bandwidth are desirable for UWB systems [6-10]. Compact printed antennas are more appropriate to be used in modern UWB systems and hence, so many activities focus on them [11-12]. Consequently, in the open literatures, various planar UWB antennas with excellent performances have been presented [1315].

As is well known, the operation band of UWB communication technology overlaps that of some other existing narrowband services like WLAN which may cause electromagnetic signal interference. Therefore, UWB antennas with a band-stop performance are required. Different 
methods such as etching slots with various shapes in the microstrip feedline, loading resonators etched on the radiator, or on the ground plane and utilizing EBG structures have been addressed to obtain UWB operation with the capability of band rejection [16-19].

A new UWB planar antenna with improved frequency bandwidth along with a band rejection for WLAN spectrum is presented. By modifying the radiation and ground planes of the introduced monopole antenna, a super wide bandwidth of $148 \%$ (from 3.1 to $24 \mathrm{GHz}$ ) is obtained for return loss function less than $-10 \mathrm{~dB}$. In addition, by placing the protruded parasitic arms, a notched band is implemented to reject the $5.5 \mathrm{GHz}$ WLAN band. The antenna has a compact size of $\mathrm{W}_{\mathrm{S}} \times \mathrm{L}_{\mathrm{S}}=20 \times 25 \mathrm{~mm}^{2}$ and provides sufficient properties. Furthermore, a $4 \times 4$ MIMO configuration of the antenna is studies. Section II presents the schematic and design details. Its fundamental characteristics are discussed in section III. Section IV investigates the MIMO performance of the antenna. The last Section will conclude this study.

\section{Design Details}

Figure 1 illustrates the schematic of the antenna. Its structure contains a modified radiation patch with a circular-ring shape with a pair of protruded arms and a cross-strip inside and also a modified semi-circular ground plane with FR4 dilectric substrate. The details of the proposed CPW fed monopole antenna are specified in Table. I. The introduced monopole antenna has been fed by using a coplanar waveguide (CPW) feeding technique [20-22]. The CPW-fed antennas are widely used in various applications owing to their excelent characteristics including compact-profile, conformal design, and ext.

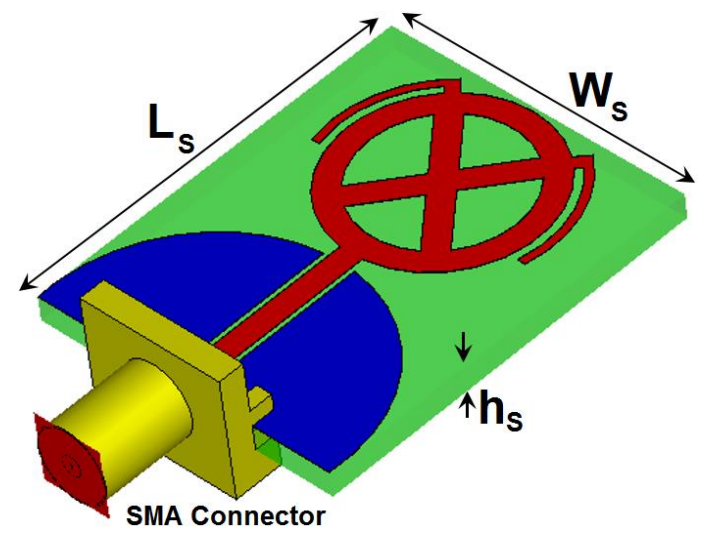

(a)

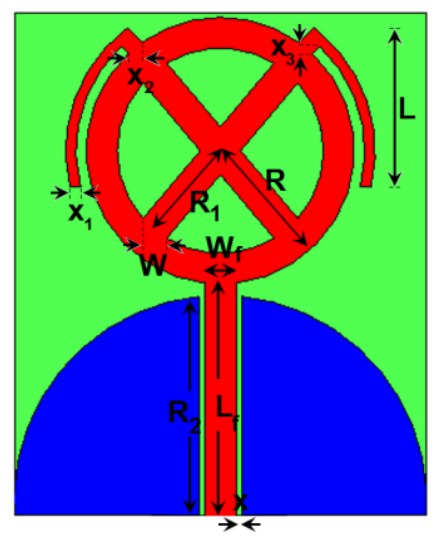

(b)

Fig. 1. Transparent (a) side and (b) front views of the proposed monopole antenna design.

Table 1. Dimensions (in millimeters) of the antenna.

\begin{tabular}{|c|c|c|c|c|c|c|}
\hline Param. & $\mathrm{W}_{\mathrm{s}}$ & $\mathrm{Ls}$ & $\mathrm{L}$ & $\mathrm{W}_{\mathrm{f}}$ & $\mathrm{Lf}_{\mathrm{f}}$ & $\mathrm{x}$ \\
\hline$(\mathbf{m m})$ & 20 & 25 & 7.7 & 3 & 11.8 & 0.3 \\
\hline Param. & $\mathrm{W}$ & $\mathrm{R}$ & $\mathrm{R}_{1}$ & $\mathrm{x}_{1}$ & $\mathrm{x}_{2}$ & $\mathrm{x}_{3}$ \\
\hline$(\mathbf{m m})$ & 1.5 & 6.5 & 5 & 0.5 & 0.85 & 0.5 \\
\hline
\end{tabular}




\section{The Characteristics of the Antenna}

Return loss results of the circular-ring monopole (Fig. 2 (a)), with a modified ground (Fig. 2 (b)), with a cross-strip (Fig. 2 (c)), and the presented antenna design (Fig. 2 (d)) are studied and compared in Fig. 3. It can be observed that the conventional circular-ring antenna cannot achieve a good impedance bandwidth covering UWB spectrum [23-24]. However, by modifying the ground plane to the semi-circular shape, the antenna frequency response in the spectrum range of 7 to $11 \mathrm{GHz}$ has been improved. In addition, by adding a cross-strip, the antenna exhibits a good return loss characteristic covering 3.1 to $24 \mathrm{GHz}$. Finally, to generate a bandnotch, a pair of parasitic arms are inserted in the radiation patch of the monopole antenna.

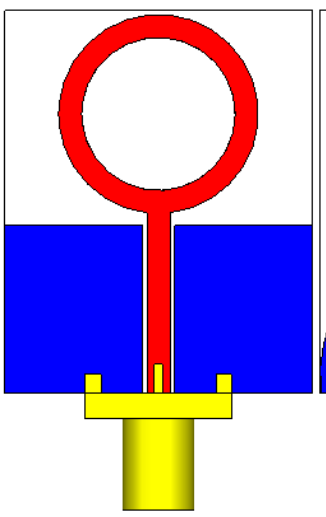

(a)

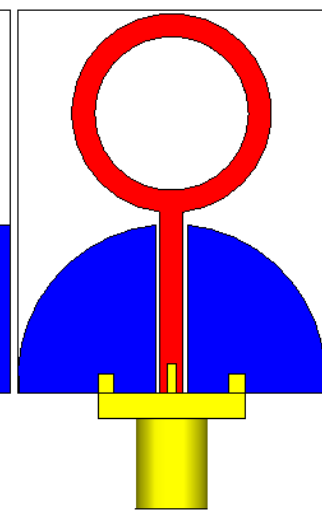

(b)

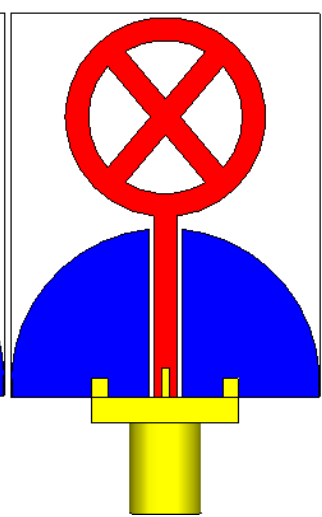

(c)

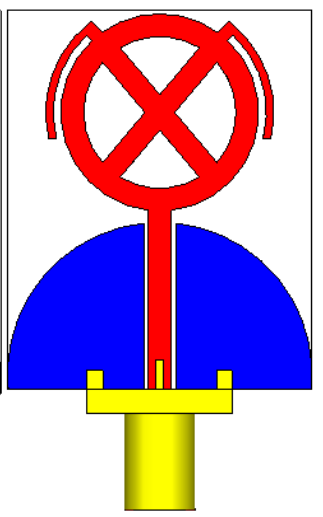

(d)

Fig. 2. Design evolutions: (a) with circular-ring resonator, (b) with a modified ground structure, (c) with the modified patch and ground structures, and (d) the main design.

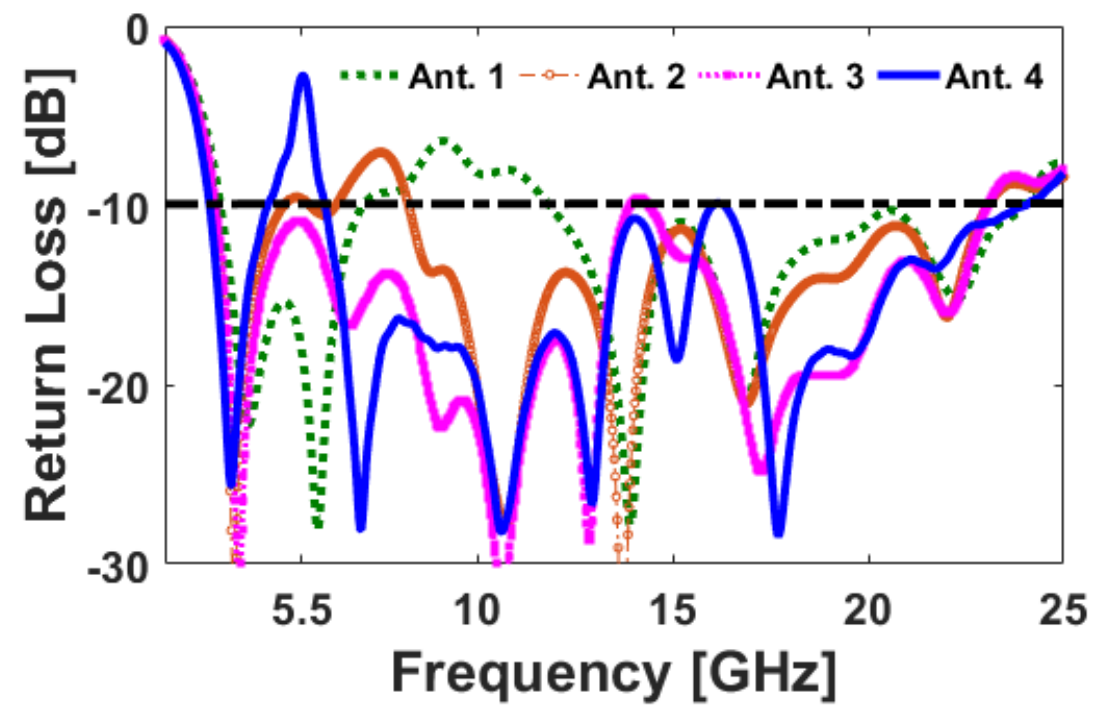

Fig. 3. Return loss results for various evolutions represented in Fig. 2. 


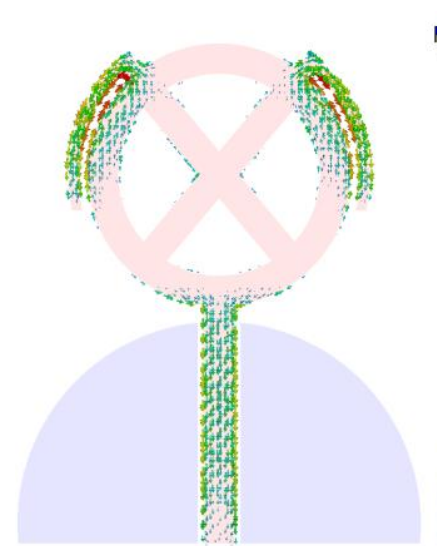

(a)

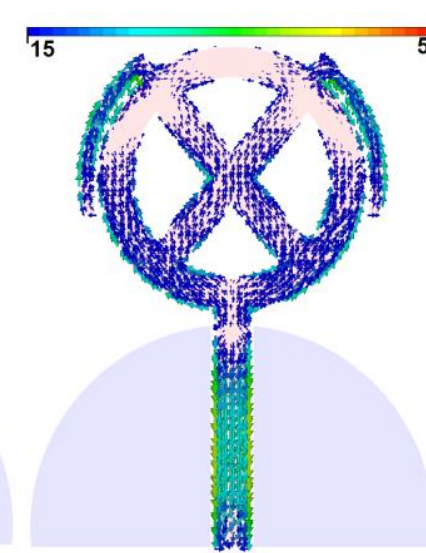

(b)

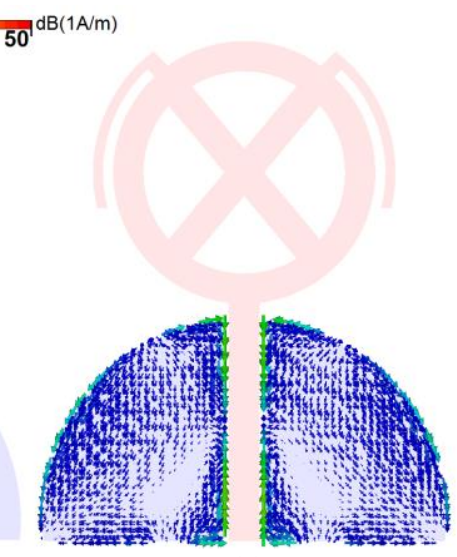

(c)

Fig. 4. Surface current distributions at (a) $5.5 \mathrm{GHz}$, (b) $6.5 \mathrm{GHz}$, and (c) $10 \mathrm{GHz}$.

To further demonstrate the working mechanism of the design, the current distributions at 5.5 $\mathrm{GHz} 7 \mathrm{GHz}$, and $10 \mathrm{GHz}$ are depicted in Fig. 4. It is evident from Fig. 4 (a), at $5.5 \mathrm{GHz}$ (notched), the employed parasitic arms are highly active. According to the current at $7 \mathrm{GHz}$, it can be found that the flows have been more dominant for the cross-strip inside the circular-ring radiation which verifies its impact on improving the antenna bandwidth at the $7 \mathrm{GHz}$. Furthermore, from Fig. 4 (c) and compared with Fig. 3, the semicircular ground plane can enhance the antenna bandwidth at upper band of UWB spectrum [25-27]. It should be noted that different configurations of the design exhibit sufficient performance in the upper spectrums (13$24 \mathrm{GHz})$.

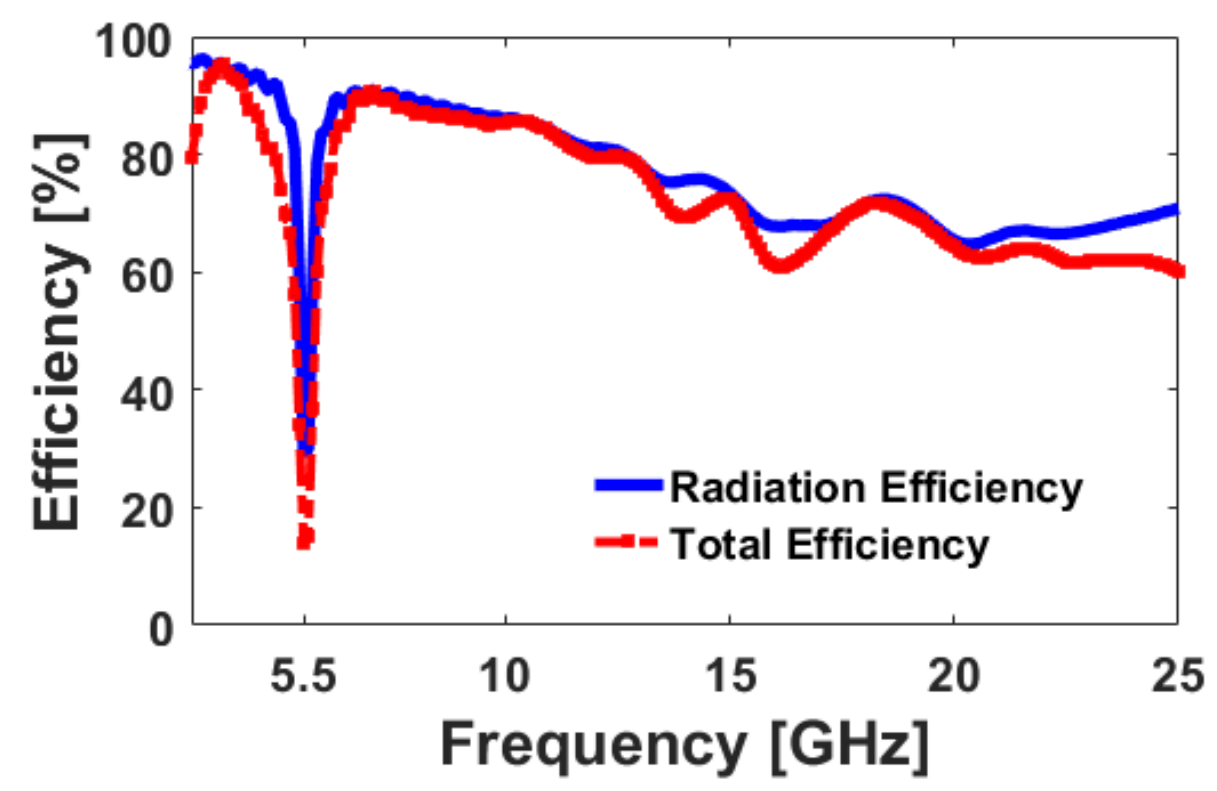

Fig. 5. Efficiencies versus frequency. 
The simulated efficiencies of the presented antenna are illustrated in Fig. 5. As seen, the presented antenna provides good efficacy characteristics. Obviously, the efficiencies fall sharply in the notch frequency $(5.5 \mathrm{GHz})$, since the radiated power is reflected back to the antenna [2831]. Apart from the notch frequency, the antenna provides higher than $65 \%$ efficiencies. Figure 6 depicts the 2D patterns in $\mathrm{H}$ - and E- plane. Because of the symmetrical structure, consistent radiation patterns are obtained for the antenna. As seen, quasi Omni-directional radiation in $\mathrm{H}-$ plane and quasi 8-shaped in E-plane are observed [32-36]. However, the radiation patterns a bit deteriorated. The gain characteristic is depicted in Fig. 7. As seen, the antenna offers sufficient gain levels over its operation band. In addition, a sharp decrease is observed at the notch frequency.

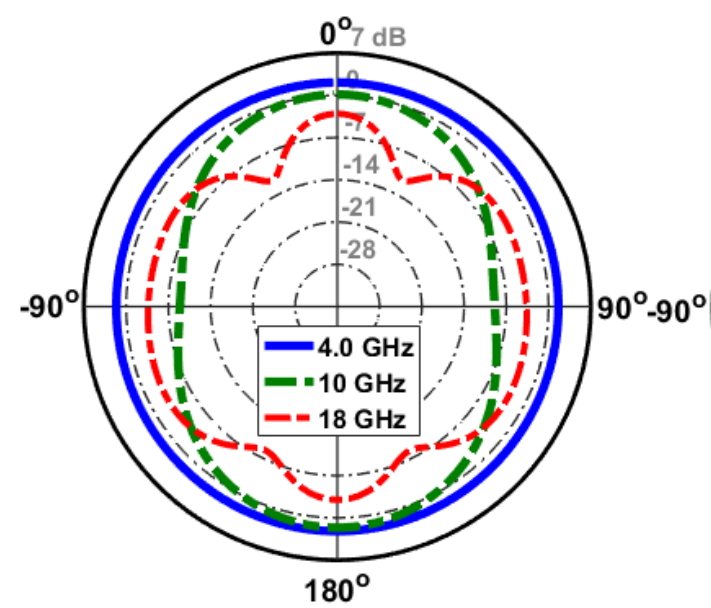

(a)

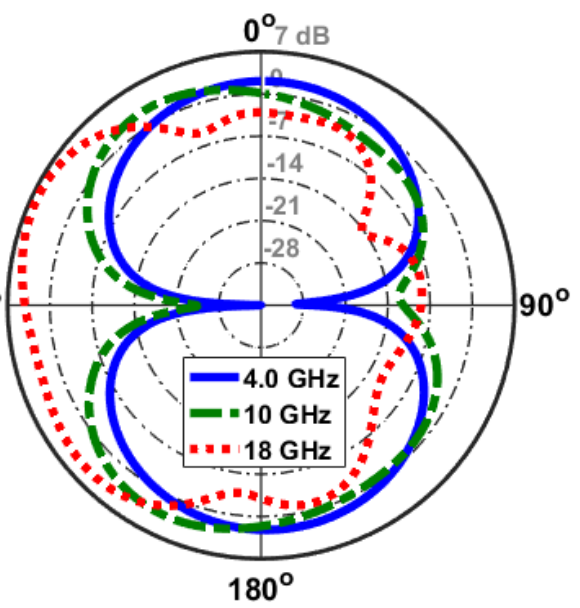

(b)

Fig. 6. (a) H-plane and (b) E-plane of the radiation.

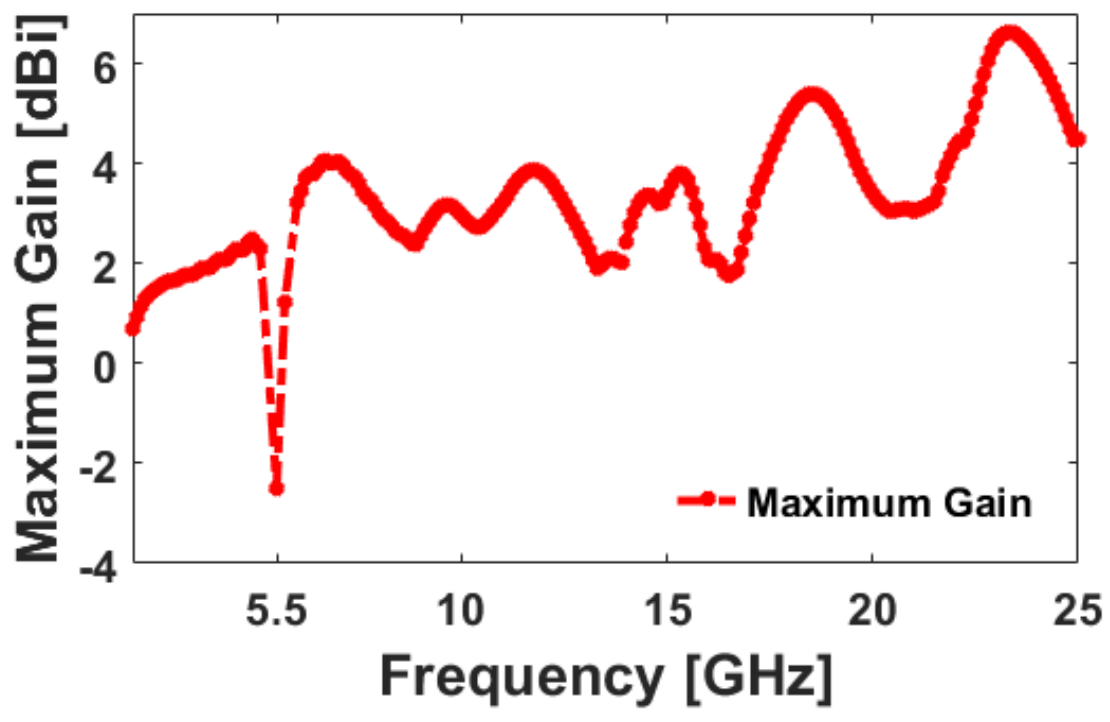

Fig. 7. Maximum gain results. 


\section{MIMO Configuration of the Design}

A MIMO structure of the presented planar monopole is designed, illustrated in Fig. 8. It contains 4 antennas placed at different sides of the dielectric with the size of $45 \times 45 \mathrm{~mm}^{2}$. Figure 9 illustrates the scattering parameter curves of the MIMO system. It is clearly shown that the MIMO design exhibits good S-parameters working at the same bandwdith of the basic design with sufficient mutual coupling [37-40].

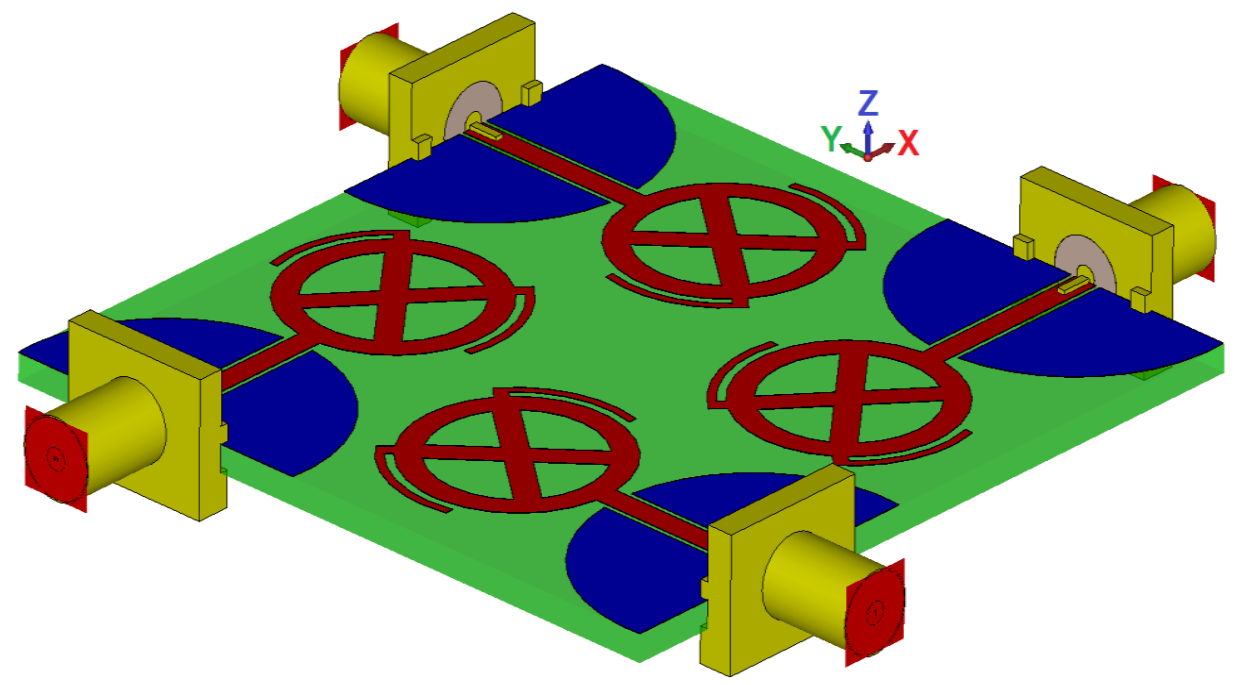

Fig. 8. $4 \times 4$ MIMO structure of the band-notched antenna.

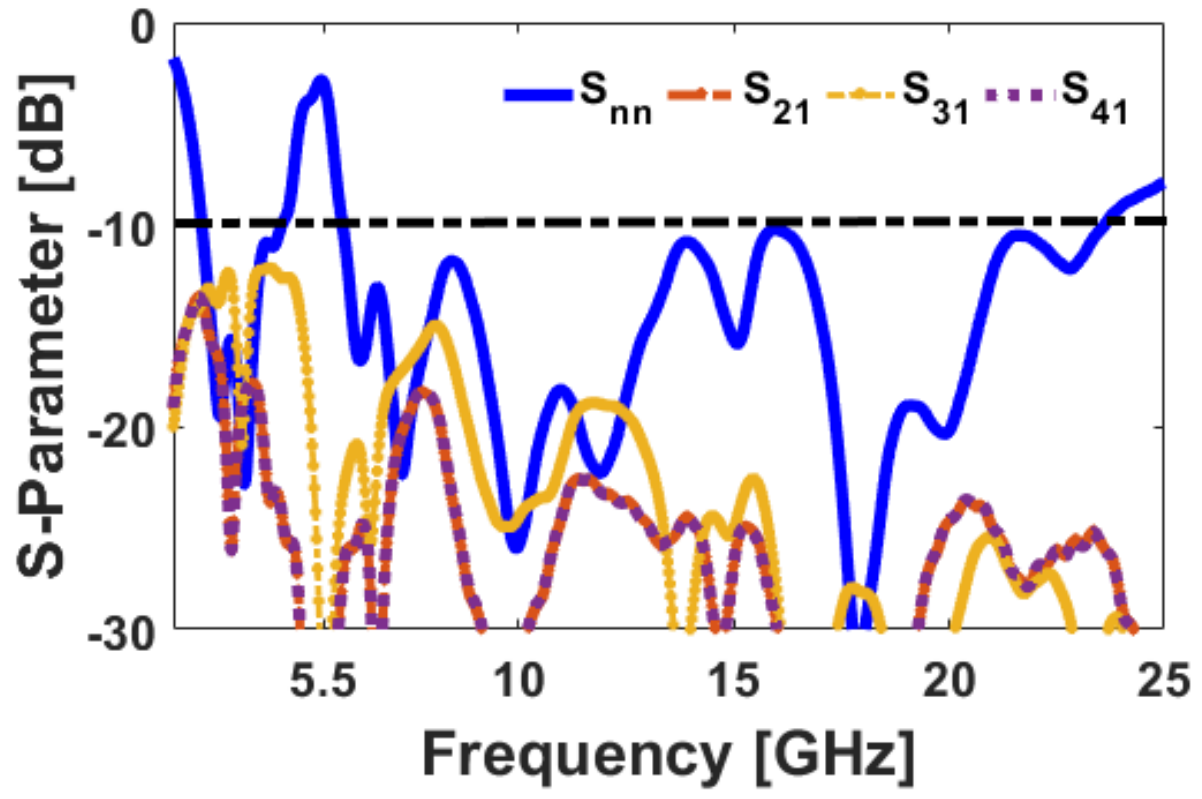

Fig. 9. S-parameters of the MIMO structure. 


\section{Conclusion}

Design and performance of a planar UWB antenna with WLAN band-stop are studied. The antenna structure contains a CPW circular-ring patch and a semicircular ground plane. By using the modified ground plane and also adding a cross-strip, the antenna bandwidth is improved. The band-notched function of the design is generated by inserting a pair of parasitic arms on the main radiators. Based on the research work discussed above, the notch behavior and bandwidth improvement characteristics are achieved with straightforward structure and novel. The antenna offers good performances and covers the frequency range of 3.1-24 GHz with a notch frequency band at $5.5 \mathrm{GHz}$. Consistent radiation behavior with approximately flat gain results are observed, except at the notched band. It also exhibits good MIMO performance in $4 \times 4$ planar form.

Acknowledgments. This work is supported by the European Union's Horizon 2020 research and innovation programme under grant agreement H2020-MSCA-ITN-2016 SECRET-722424.

\section{References}

[1] Reed, J.H.: An introduction to ultra-wideband communication systems. Prentice Hall Press, pp.1-50, (2005)

[2] Allen, B. et al.: Ultra-wideband antennas and propagation for wireless communications, radar, and imaging. John Wiley \&Sons, USA (2007)

[3] Parchin, N. O. et al.: A substrate-insensitive antenna array with broad bandwidth and high efficiency for 5G mobile terminals," Photonics \& Electromagnetics Research Symposium (PIERS), Xiamen, China (2019)

[4] Ojaroudi, M. et al.: Dual band-notch small square monopole antennawith enhanced bandwidth characteristics for UWB applications.ACES J. Vol. 25, pp.420-426 (2012).

[5] Federal Communications Commission. First Report and Order on Ultra-Wideband Technology. FCC 02-48, Washington. April 22 (2002)

[6] Wiesbeck, W. Adamiuk, G. and Sturm, C.: Basic properties and design principles of UWB antennas. Proc. IEEE. pp. 372-385 (2009)

[7] Parchin, N. O. et al.: Microwave/RF components for $5 \mathrm{G}$ front-end systems, Avid Science (2019)

[8] Ojaroudi, N.: A new design of koch fractal slot antenna for ultra-wideband applications. $21^{\text {th }}$ Telecommunications Forum. TELFOR 2013, 27 - 28 November, Belgrade, Serbia (2013)

[9] Akbarzadeh, $\mathrm{H}$. et al.: Utilization of protruded strip resonators to design a compact UWB antenna with WiMAX and WLAN notch bands. ACES Journal, Vol. 31, pp. 159-163 (2016)

[10] Siahkal-Mahalle, B. H. et al.: A new design of small square monopole antenna with enhanced bandwidth by using cross-shaped slot and conductor-backed plane. Microwave Opt Technol Lett, vol. 54, pp. 2656-2659 (2012)

[11] Ojaroudiparchin, N. et al.: Wide-scan phased array antenna fed by coax-to-microstriplines for 5G cell phones. MIKON Conference, Krakow, Poland, May (2016)

[12] Parchin, N. O. et al.: Frequency reconfigurable antenna array for mm-Wave 5G mobile handsets. BroadNets, Faro, Portugal, 19-20 September (2018)

[13] Wang, L. et al.,: Compact UWB MIMO antenna With high isolation using fence-type decoupling structure. IEEE Antennas and Wireless Propagation Letters. pp.1641-1645 (2019)

[14] Azim, R., Islam, M.T., and Misran, N.: Compact tapered-shape slot antenna for UWB applications. IEEE Antennas Wireless Propag. Lett. pp. 1190-1193 (2011)

[15] Siahkal-Mahalle, B.H. et al.: Enhanced bandwidth small square monopole antenna with bandnotched functions for UWB wireless communications. Applied Computational Electromagnetics Society (ACES) Journal. pp. 759-765 (2012)

[16] Parchin, N.O. et al.: Gain improvement of a UWB antenna using a single-layer FSS. PhotonIcs \& Electromagnetics Research Symposium (PIERS). Xiamen-China. 17-20 December (2019) 
[17] Ojaroudi, N. et al.: UWB omnidirectional square monopole antenna for use in circular cylindrical microwave imaging systems. IEEE Antennas Wireless Propag. Lett. pp. 1350-1353 (2012)

[18] Ojaroudi, N.: Small microstrip-fed slot antenna with frequency band-stop function. $21^{\text {th }}$ Telecommunications Forum. TELFOR 2013, 27 - 28 November, Belgrade, Serbia (2013)

[19] Valizade, A., Ghobadi, Ch., Nourinia, J., Ojaroudi, N., Ojaroudi, M.: Band-notch slot antenna with enhanced bandwidth by using $\Omega$-shaped strips protruded inside rectangular slots for UWB applications. Appl. Comput. Electromagn. Soc. (ACES) J. pp. 816-822 (2012)

[20] Horestani, A.K. et al.: Reconfigurable and tunable S-shaped split-ring resonators and application in band-notched UWB antenna. IEEE Trans. Antennas Propag. pp. 3766-3776 (2016)

[21] Valizade, A. et al.: CPW-fed small slot antenna with reconfigurable circular polarization and impedance bandwidth characteristics for DCS/WiMAX applications. Progress in Electromagnetics Research C. pp. 65-72 (2015)

[22] Ojaroudi, N.: Design of ultra-wideband monopole antenna with enhanced bandwidth," $21^{\text {th }}$ Telecommunications Forum. TELFOR 2013, Belgrade, Serbia, 27 - 28 November (2013)

[23] Ojaroudi, N. and Ghadimi, N.: "Dual-band CPW-fed slot antenna with a pair of hook-shaped slits. Microw. Opt. Technol. Lett. pp.172-174 (2015)

[24] $\mathrm{Li}$, T. et al.,: Compact UWB antenna with tunable band-notched characteristic based on microstrip open-loop resonator. IEEE Antennas Wireless Propag. Lett., pp. 1584-1587 (2012)

[25] Horestani, A. K. et al.: Reconfigurable and tunable S-shaped split-ring resonators and application in band-notched UWB antennas. IEEE Trans. Antennas Propag. pp. 3766-3776 (2016)

[26] Kamalvand, A. et al.: Omni-directional/multi-resonance CPW-fed small slot antenna for UWB applications. ACES Journal. pp. 829-835 (2013)

[27] Ojaroudi, N.: Design of small reconfigurable microstrip antenna for UWB-CR applications. 19th International Symposium on Antenna and propagation, ISAP2014, Kaohsiung, Taiwan, Dec. 2-5 (2014)

[28] Ojaroudi, N.: Circular microstrip antenna with dual band-stop performance for ultra-wideband systems. Microw. Opt. Technol. Lett. Vol. 56, pp.2095-2098 (2014)

[29] Abdollahi, M. M. et al.: Octave-band monopole antenna with a horseshoe ground plane. ACES Journal, Vol. 30, pp.773-778 (2015)

[30] Parchin, N. O. et al.: Frequency reconfigurable antenna array for mmWave $5 \mathrm{G}$ mobile handsets, BroadNets, Faro, Portugal, 19-20 September (2018)

[31] Zolghadr, J. et al.: UWB slot antenna with band-notched property with time domain modeling based on genetic algorithm optimization. ACES Journal, Vol. 31, pp.926-932 (2016)

[32] M. Bahmani, et al., "A compact UWB slot antenna with reconfigurable band-notched function for multimode applications," ACES Journal, vol. 13, no. 1, pp. 975-980, 2016.

[33] Mazloum, J. et al.: Bandwidth enhancement of small slot antenna with a variable band-stop function. Wireless Personal Communications. Vol. 95, pp.1147-1158 (2017)

[34] Ullah, A. et al.: Coplanar waveguide antenna with defected ground structure for $5 \mathrm{G}$ millimeter wave communications. IEEE MENACOMM'19, Bahrain (2019)

[35] Parchin, N. O.: Low-profile air-filled antenna for next generation wireless systems. Wireless Personal Communications. Vol. 97, pp.3293-3300 (2017)

[36] Mazloum, J. et al.: Compact triple-band S-shaped monopole diversity antenna for MIMO applications. ACES Journal, Vol. 28, pp.975-980 (2015)

[37] Basherlou, H. J. et al.: MIMO monopole antenna design with improved isolation for 5G WiFi applications. International Journal of Electrical and Electronic Science. Vol. 7, pp.1-5 (2019)

[38] Parchin N. O. et al.: Eight-element dual-polarized MIMO slot antenna system for 5G smartphone applications. IEEE Access, pp.15612-15622 (2019)

[39] Parchin, N. O. Abd-Alhameed, R. A.: A compact Vivaldi antenna array for 5G channel sounding applications. EuCAP, London, UK (2018)

[40] Parchin, N. O. et al.: High-performance Yagi-Uda antenna array for $28 \mathrm{GHz}$ mobile communications," $23^{\text {th }}$ Telecommunications Forum, 25-27 November, Belgrade, Serbia (2019) 